\title{
A Comparison of the Stability Performance of Blends of Paraffinic Diesel and Petroleum-Derived Diesel, with RME Biodiesel Using Laboratory Stability Measurement Techniques
}

\author{
S. de Goede, ${ }^{1}$ C. Wilken, ${ }^{1}$ M. Ajam, ${ }^{1}$ P. Roets, ${ }^{1}$ P. Engelbrecht, ${ }^{1}$ and C. Woolard ${ }^{2}$ \\ ${ }^{1}$ Sasol Southern Africa Energy, Energy Technology, Sasolburg 1947, South Africa \\ ${ }^{2}$ Sasol Advanced Fuels Laboratory, University of Cape Town, Cape Town 7700, South Africa
}

Correspondence should be addressed to S. de Goede; stefan.degoede@sasol.com

Received 30 July 2014; Accepted 23 January 2015

Academic Editor: Xingcai Lu

Copyright (C) 2015 S. de Goede et al. This is an open access article distributed under the Creative Commons Attribution License, which permits unrestricted use, distribution, and reproduction in any medium, provided the original work is properly cited.

In 2012, a new specification for synthetic fuels containing up to 7\% biodiesel (FAME) was approved (CEN TS 15940). This specification allows the sale of neat paraffinic diesel, such as Gas-to-Liquids (GTL) diesel, to captive fleets in Europe. Several aspects are important in the final end-use application, including the stability of the fuel. The current study evaluated the stability of neat GTL diesel and FAME/paraffinic fuel blends via standard laboratory stability tests commonly used to study petroleum-derived fuels. The stability of GTL diesel, containing biodiesel, was evaluated using the Rancimat, PetroOxy, and ASTMD2274 tests. Selected samples were also evaluated using ASTM D5304. The Rancimat results indicated that FAME/GTL diesel blends performed similar to the FAME/petroleum derived fuel blends. In the PetroOxy test, the addition of more than $2 \mathrm{v} / \mathrm{v} \%$ of a highly stable FAME resulted in an unexpected boost in the stability of the FAME/GTL diesel blend. The ASTM D2274 results were generally insensitive to the addition of FAME. The correlation between the PetroOxy and Rancimant tests was evaluated and found to be base fuel dependent. From this study it was concluded that GTL diesel (in blends with FAME) performed similar to petroleum-derived reference fuels in standard laboratory stability.

\section{Background}

1.1. General Introduction. Diesel is an important transportation fuel and, in several countries, the demand for diesel far exceeds the demand for petrol (gasoline) [1]. Diesel engines have gained popularity over gasoline engines owing to lower fuel consumption because of higher thermal efficiency and the higher volumetric energy density of diesel [2]. The stability of diesel is critical in ensuring problem-free use in the market. Some of the approaches of ensuring that a diesel maintains its properties during use include strict production specifications (limiting contaminants), adding antioxidants (especially in biodiesel), and good housekeeping during storage and use. Petroleum-derived diesels are generally highly stable and will remain stable for several years, depending on storage conditions [3]. In recent years, the fuels landscape has changed dramatically, with several alternative fuels and fuel components entering the diesel pool. Fuels or fuel components like Fischer-Tropsch (FT) fuels (specifically Gasto-Liquids (GTL) diesel) and Hydrotreated Vegetable Oils (HVOs) are generally considered to be stable, while components like biodiesel (especially fatty acid methyl esters (FAME)) are considered to be significantly less stable than petroleumderived diesel and may require antioxidants to maintain their stability [4]. There are some contradictory conclusions in literature on the stability of FAME/paraffinic diesel blends. The majority of authors indicate good stability [5-7] but Mushrush et al. [8] indicated that blends of soy biodiesel and FT diesel were unstable under oxidative conditions. Mushrush et al. evaluated samples using the ASTM D5304 test. The method is an accelerated oxidative test and will be discussed further in Table 1. Using this test, they found that 


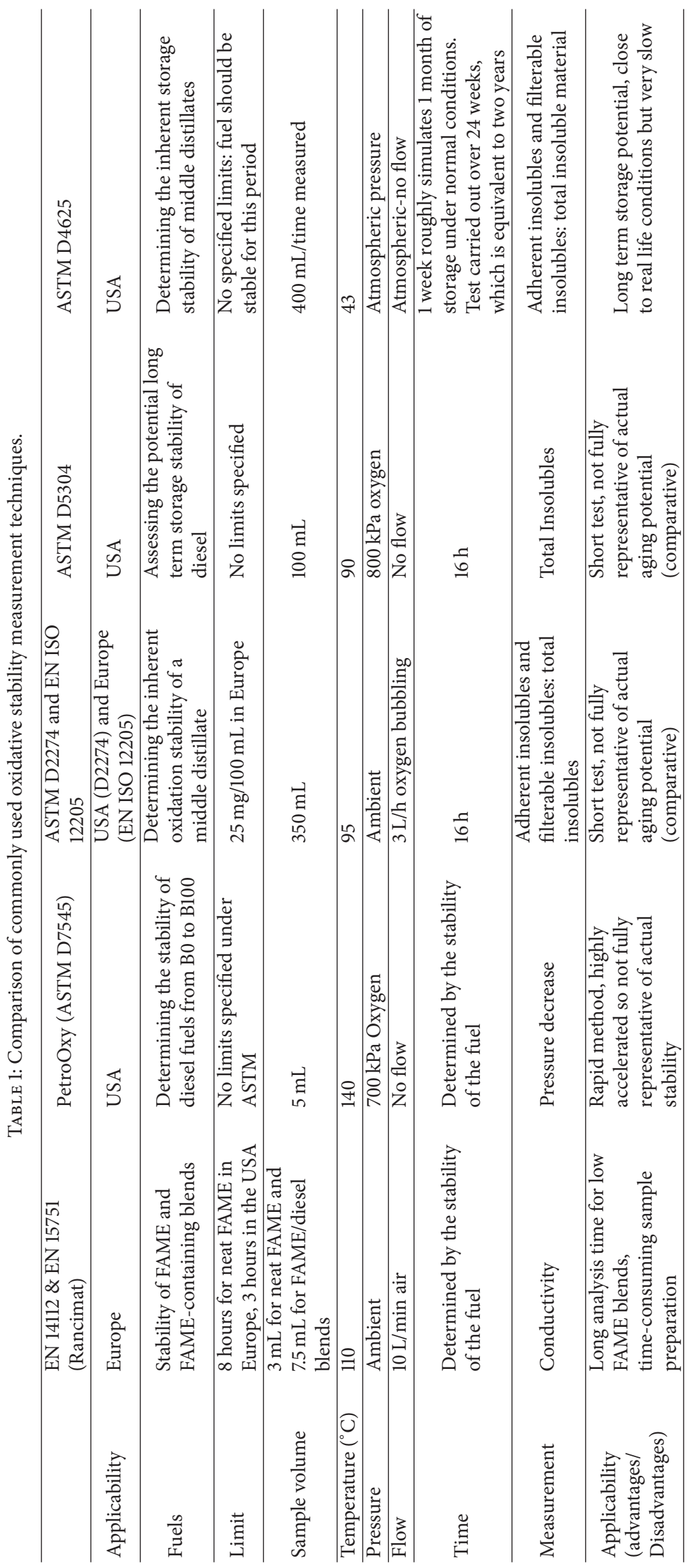


blends of soy biodiesel and FT diesel were extremely unstable, resulting in very high levels of deposits. In line with the recently approved CEN TS15940:2012 specification, the performance of FAME/paraffinic fuels in standard laboratory stability tests is important to understand, in order to ensure that these tests are applicable and provide relevant information on the stability of these fuels.

Should a diesel fuel not be stable, sediment may form, which may block fuel filters [9]. Terry et al. [10] showed that at high extents of oxidation, two phases may form, which is detrimental to fuel pumps and may also cause other operational problems. Acids will form during the degradation process [11] and these acids may result in the corrosion of metal parts in an engine. In extreme cases, enough deposits may form to cause filter plugging [12].

Although petroleum-derived diesel is generally highly stable, it is well known that diesel, like many other petroleumderived products, will exhibit instability when exposed to high temperatures and conditions favouring oxidation reactions [12]. Fuel composition has a critical influence on the stability of a diesel. Diesels that contain no olefins are generally more stable than olefin-containing fuels. The addition of stabilisers, for example, antioxidants, and several other compositional factors can dramatically improve the stability of a fuel [12].

1.2. Paraffinic Diesel Stability. There are two main types of commercially available paraffinic fuels that may be blended with conventional diesel fuel:

(1) Fischer Tropsch diesel (including Gas-to-Liquids, coal-to-liquids, and biomass-to-liquids),

(2) Hydrotreated Vegetable Oils (HVOs), produced by hydrogenating vegetable oils.

Gas-to-Liquids (GTL) diesel is highly paraffinic and contains little or no sulphur- and nitrogen-containing compounds [13]. These compounds are removed during the production process. GTL diesel is hydrotreated to remove any olefins and oxygenates. Because of the absence of these heteroatoms (present in nitrogen-, sulphur- and oxygen-containing molecules), it is expected that these fuels will inherently be very stable. However, paraffinic fuels do not contain any naturally occurring heteroatomic antioxidants (inhibitors) to promote stability. Once degradation starts, GTL diesel has no inherent ability to prevent or inhibit further oxidation.

Several papers have shown excellent performance for neat GTL diesel in the ASTM D2274 test $[14,15]$ as a neat fuel or blended with petroleum-derived diesel. In a report by NREL, GTL diesel stability was measured using ASTM D2274 and ASTM D6468 [16]. It was shown that around $0.4 \mathrm{mg} / 100 \mathrm{~mL}$ of deposits formed in the ASTM D2274 test (stable fuel) and that an ASTM D6468 reflectance value of 100\% (excellent stability) was achieved with GTL diesel. There has been some indication that Fischer Tropsch fuels may display unexpected lower stability in certain blends (i.e., namely, in blends with poor stability LCO [17]). In contrast, this behaviour was not observed by Velaers and de Goede [6], although the fuel matrix employed in this study contained stable EN590 diesel fuels, rather than potentially unstable fuel components such as the LCO studied by O'Rear et al. [17].

Similar stability claims have been made for Hydrotreated Vegetable Oils (HVOs) [18]. Kuronen et al. [18] indicated that HVO diesel was highly stable in the EN ISO 12205 test. Similar to ASTM D2274, the test is conducted over 16 hours at $95^{\circ} \mathrm{C}$ while bubbling pure oxygen through the sample. It was shown that $\mathrm{HVO}$ always resulted in an insolubles concentration of less than $5 \mathrm{~g} / \mathrm{m}^{3}$, compared to a maximum limit of $25 \mathrm{~g} / \mathrm{m}^{3}$ specified in EN590. It was also shown that HVO performed very well in the EN 14112 test, with an induction time of over 40 hours, which is well above the 20 hours limit in EN590.

1.3. The Stability of FAME Biodiesel. Although biodiesel (FAME) has several good properties from a diesel perspective, it is well known that FAME, produced from soy, rapeseed, tallow, and several other feedstocks is less stable than petroleum-derived diesel $[4,19]$. Typically, biodiesel can degrade through three mechanisms [19]:

(1) oxidation via the interaction with oxygen in air. As neat and blended FAME may be stored for extensive periods of time, oxidative stability is very important for FAME,

(2) thermal or thermooxidative degradation due to exposure to temperatures above ambient,

(3) hydrolysis of the FAME molecules in the presence of water.

Degradation of FAME can result in several issues: it may impair fuel quality and may also have an effect on engine/ hardware performance [19]. The instability of biodiesel is generally attributed to unsaturation, present in the fatty acid chains. Most fatty acids (and therefore the corresponding FAME molecules) contain double bonds (unsaturation) which would result in degradation of the molecules with time, especially if the FAME is stored for extended periods of time [4]. Different feedstocks contain different amounts of unsaturation. Depending on environmental factors such as temperature and/or exposure to air, this decrease in stability with time may be very large. Factors such as exposure to light, high temperatures, and certain contaminants, especially metals like copper $[4,19]$, may make the problem worse.

Biodiesel stability and degradation have been widely researched and consensus has been reached about the general mechanism of neat FAME degradation [9]. Biodiesel typically consists of methyl esters of $\mathrm{C}_{16}$ and $\mathrm{C}_{18}$ carboxylic acids, containing between 0 and 3 unsaturated bonds. In a poly unsaturated chain, the double bonds are typically not conjugated but separated by a methylene $\left(\mathrm{CH}_{2}\right)$ group, known as a bisallylic group. For the $\mathrm{C}_{18}$ carboxylic acid esters containing one double bond, the molecule is known as oleic acid, 2 = linoleic and $3=$ linolenic acid. Generally, the rate of oxidation of FAME increases with an increase in the number of double bonds and the position of the double bonds. The oxidative stability of the molecules decreases in the following order [19]:

Oleic $\gg$ Linoleic $>$ Linolenic 
This is mainly due to the triunsaturated molecules having more reactive sites for the initiation of degradation than the monounsaturated chains. The stability of biodiesel is significantly influenced by the number and position of bisallylic methylene moieties, rather than by the number of double bonds [19]. These sites serve as initiation sites and will initiate the degradation cycle.

Exact modelling of the stability performance of FAME is difficult: this is due to the number of factors playing a role in determining the final fuel stability [20].

Several countries have introduced minimum stability criteria for neat FAME, mainly based on the Rancimat test (EN14112 and EN15751). In Europe, a minimum Rancimat induction time of 8 hours is specified (previously 6 hours), while, in the USA, a minimum of 3 hours is required. It is important to remember that most vegetable oils contain natural antioxidants. A typical example is tocopherols, which is a hindered phenolic molecule. This may, however, be removed during some of the purification steps during the biodiesel production.

Although petroleum-derived diesels are generally stable for relatively long periods, the addition of even small quantities of FAME will result in a significant decrease in the stability of the FAME/petroleum-derived diesel blend.

1.4. The Stability of FAME/FT Diesel Blends. Limited information exists in the open literature on the stability of FAME/ FT diesel blends. This may be the result of FT diesel being used primarily as a blend component in petroleum-derived fuels, typically only up to a maximum of $20 \mathrm{v} / \mathrm{v} \%$ FT diesel [6].

Mushrush et al. $[8,21]$ studied the stability of three-component blends (ULSD, SME, and FT diesel). In this study, ASTM D5304 was used to evaluate the stability of the fuels. A value of less than $3 \mathrm{mg} / 100 \mathrm{~mL}$ is considered stable during storage. Although the neat petroleum-derived diesel and the FT diesel on their own performed satisfactorily, Mushrush et al. found extremely high levels of deposits for soy biodiesel/ FT diesel blends and ternary blends of FT diesel, petroleum diesel, and soy biodiesel. The industry consensus at present is however, that these oxidative tests, like ASTM D2274, are only applicable to blends containing up to $2 \%$ FAME after which Rancimat is the recommended stability measurement technique [22].

Blignaut et al. [23] investigated the Rancimat stability of low temperature Fischer Tropsch (LTFT) GTL diesel and high temperature Fischer Tropsch (HTFT) diesel with soy and rapeseed biodiesels. Blends containing $0.5,1,5,7,10$, and $20 \%$ were compared using Rancimat analysis. Both biodiesels were additised with antioxidants and complied with the EN14214 specification. It was shown that FAME/LTFT diesel blends were generally more stable than FAME/petroleum-derived diesel.

De Goede et al. [7] showed similar trends for FAME/GTL diesel blends in comparison to FAME/E590 diesel blends. FAME/GTL diesel blends generally outperformed equivalent FAME/EN590 diesel blends.
In a provisional patent filing by Shell, [24] the stability of blends was compared. The blends contained:

(i) $50-90 \%$ petroleum-refined diesel, containing less than $500 \mathrm{ppm}$ sulphur and a boiling point in the range of $150-400^{\circ} \mathrm{C}$,

(ii) 5-25\% FT derived diesel,

(iii) 5-25\% fatty acid alkyl ester (FAME/FAEE).

In this patent application, Cherrillo et al. used the Jet Fuel Thermal Oxidation Test (JFTOT) instrument and performed a procedure similar to ASTM D3241, commonly used for the determination of jet fuel stability. It was found that at specific blending ratios (in one example 90\% ULSD, 5\% GTL diesel, and 5\% SME) the blend showed significantly improved stability compared to the neat petroleum-derived ULSD. This effect was not seen for neat SME or a 95\% ULSD/5\% GTL diesel blend. A possible explanation for this phenomenon was that, under the right conditions of temperature and composition, SME molecules or polar degradation products from the SME can act as surface active components to maintain cleanliness of surfaces subjected to deposits from hydrocarbon fuels [24].

\section{Stability Measurement Techniques}

Several stability techniques have been developed to determine the inherent stability of a diesel. Most of these techniques are conducted at elevated temperatures (to shorten the analysis time). These techniques may not necessarily correlate with field experience [5], as the degradation mechanisms applicable under the higher temperature conditions, typical of these accelerated tests, may not be representative of those under normal conditions.

The typical laboratory stability testing techniques are evaluated in Table 1.

\section{Experimental}

3.1. Fuels Evaluated in This Study. In the current study, the following fuels (neat and blended) were evaluated. The properties of the fuels are given in Tables 5-8.

(1) US 2-D diesel: this was a specially blended commercial reference fuel, blended from component streams. The properties of this fuel are given in Table 5. It was unclear if this fuel contained any antioxidant, although no indications were given on the certificate of analysis (CoA).

(2) EN590 diesel: this was a refinery reference fuel, specifically blended to be representative of a typical European winter diesel fuel. The properties of the neat EN590 diesel are given in Table 6. No antioxidant was present in the fuel.

(3) Commercial GTL diesel with typical "summer type" properties $\left(\mathrm{CP}=-9^{\circ} \mathrm{C}\right)$ : the properties of this fuel are given in Table 7 . The fuel contained no antioxidants.

(4) A "winter type" GTL diesel $\left(\mathrm{CP}=-43^{\circ} \mathrm{C}\right)$ : The properties of this fuel are given in Table 7 . The fuel contained no antioxidants. 
TABLE 2: Experimental matrix for studying the stability of FAME/diesel blends.

\begin{tabular}{lcc}
\hline Diesel type & Biodiesel type & RME biodiesel concentration \\
\hline US 2-D diesel & Low stability RME & $0 \%, 5 \%, 10 \%, 15 \%$ and $20 \%$ \\
US 2-D diesel & High stability RME & $0 \%, 5 \%, 10 \%, 15 \%$ and $20 \%$ \\
EN590 diesel & Low stability RME & $0 \%, 5 \%, 10 \%, 15 \%$ and $20 \%$ \\
EN590 diesel & High stability RME & $0 \%, 5 \%, 10 \%, 15 \%$ and $20 \%$ \\
"Summer type" GTL diesel & Low stability RME & $0 \%, 5 \%, 10 \%, 15 \%$ and $20 \%$ \\
"Summer type" GTL diesel & High stability RME & $0 \%, 5 \%, 10 \%, 15 \%$ and $20 \%$ \\
"Winter type" GTL diesel & Low stability RME & $0 \%, 5 \%, 10 \%, 15 \%$ and $20 \%$ \\
"Winter type" GTL diesel & High stability RME & $0 \%, 5 \%, 10 \%, 15 \%$ and $20 \%$ \\
\hline
\end{tabular}

(5) Rapeseed methyl ester (RME) biodiesel: the fuel had a Rancimat induction time of 8.8 hours and was additised with an antioxidant. This biodiesel was seen as representative of a high quality EN14212-compliant biodiesel. The properties of this fuel are given in Table 8.

(6) An aged rapeseed biodiesel, with a Rancimat induction time of 3.6 hours: this fuel had been in storage for approximately 5 years and originally contained antioxidants, although it would be fair to assume (given the low Rancimat stability) that the levels of any antioxidants present would be significantly depleted at the time of this evaluation.

3.2. Experimental Matrix. The experimental matrix was divided into two parts.

(1) The first part of this study aimed to quantify the stability performance of GTL and petroleum-derived diesel, using three different laboratory stability measurement techniques. In this part, binary blends were prepared containing $0 \%, 2 \%, 5 \%, 10 \%, 15 \%$, and $20 \mathrm{v} / \mathrm{v} \%$ FAME. The sample matrix is shown in Table 2.

(2) The second part of the investigation involved a "crossed" experimental design, which made it possible to evaluate the component blending properties, and the effects of the process variables (numerical and/or categorical). In order to design the experiment, a quadratic $(\mathrm{Q}) \times$ linear $(\mathrm{L})$ base model was specified for the "mixture $\times$ process" design. The blending of the five components together with biodiesel type (low and high stability) resulted in a 33-run optimal design. Biodiesel was restricted to a maximum concentration of $20 \%$, while the other components were allowed to vary freely, that is, $0-100 \%$ (see Table 3 ). All 33 samples were used for the PetroOxy correlations, while only the FAME-containing fuels were considered for the Rancimat analysis. The experimental design is provided in Table 9.

The advantage of this approach (compared to the first part of the investigation) is that the design matrix now includes neat components, binary, ternary, and quaternary blends. Commercially available statistical software, Design Expert [25], was used for the experimental design and statistical evaluation of the results.
TABLE 3: Experimental ranges used for studying the stability of FAME/diesel blends (crossed design).

\begin{tabular}{lcc}
\hline Diesel type & Minimum & Maximum \\
\hline US 2-D diesel & $0 \%$ & $100 \%$ \\
EN590 diesel & $0 \%$ & $100 \%$ \\
"Summer type" GTL diesel & $0 \%$ & $100 \%$ \\
"Winter type" GTL diesel & $0 \%$ & $100 \%$ \\
Biodiesel concentration & $0 \%$ & $20 \%$
\end{tabular}

Biodiesel type Low stability RME High stability RME

TABLE 4: ASTM D5304 analyses on selected neat and FAMEcontaining fuels.

\begin{tabular}{lc}
\hline Sample & Deposit weight $(\mathrm{mg} / 100 \mathrm{~mL})$ \\
\hline Neat "summer type" GTL diesel & 1.7 \\
"Summer type" GTL + 5\% RME & 2.2 \\
Neat EN590 & 1.2 \\
EN590 + 5\% RME & 0.5 \\
"Summer type" GTL + 10\% RME & 0.8 \\
EN590 + 10\% RME & 0.6 \\
"Summer type" GTL + 5\% SME & 0.6 \\
EN590 + 5\% SME & 0.8 \\
\hline
\end{tabular}

In the current investigation, Rancimat analyses [26, 27] were conducted at $110^{\circ} \mathrm{C}$ using a Metrohm 743 analyser (Metrohm, Herisau). Approximately $3 \mathrm{~g} \pm 0.1 \mathrm{~g}$ (neat biodiesel) or $7.5 \mathrm{~g} \pm 0.1 \mathrm{~g}$ (diesel/biodiesel blend) were weighed out in the standard test tubes. Neat biodiesel was analysed according to EN14112 for the neat biodiesel samples and diesel/biodiesel blends according to EN15751.

3.2.1. PetroOxy Analysis [28]. In this study, PetroOxy analyses were carried out using a Petrotest PetroOxy analyser, following ASTM D7545. Analyses were conducted at $140^{\circ} \mathrm{C}$ and an oxygen pressure of $700 \mathrm{kPa}$. A $10 \%$ decrease in the pressure was used as the end point criterion of the analysis.

3.2.2. ASTM D2274 [29]. ASTM D2274 analyses were conducted under standard experimental conditions. 
TABLE 5: Properties of the US 2-D diesel, evaluated in the current study.

\begin{tabular}{|c|c|c|c|}
\hline Property & Unit & US 2D specification & Result \\
\hline Cetane number, min & & 40 & 46.2 \\
\hline Cetane index, min & & 40 & 47 \\
\hline Sulphur (max) & ppm & 15 & 12 \\
\hline Total aromatics, max & vol $\%$ & 35 & 21.86 \\
\hline Viscosity@40 $\mathrm{C}, \min / \max$ & $\mathrm{cSt}$ & $1.9-4.1$ & 2.8 \\
\hline \multicolumn{4}{|l|}{ Distillation } \\
\hline T90 min/T90 max & ${ }^{\circ} \mathrm{C}$ & $282-338$ & 313 \\
\hline Flash point min & ${ }^{\circ} \mathrm{C}$ & 52 & 81 \\
\hline Carbon residue $10 \% \max$ & $\mathrm{w} \%$ & 0.35 & 0.05 \\
\hline Water and Sediment, max & vol\% & 0.05 & $\mathrm{NM}^{*}$ \\
\hline Ash max & $\mathrm{w} \%$ & 0.01 & $\mathrm{NM}^{*}$ \\
\hline Lubricity, HFRR wear scar diameter @ 60 $\mathrm{C}$, micron max & micron & 520 & 499 \\
\hline Copper corrosion $\left(3 \mathrm{~h} @ 50^{\circ} \mathrm{C}\right) \max$ & & No 3 & $1 \mathrm{~B}$ \\
\hline Conductivity & $\mathrm{pS} / \mathrm{m}$ & 25 & $\mathrm{NM}^{*}$ \\
\hline Dye content, max & $\mathrm{g} / 100 \mathrm{~L}$ & & $\mathrm{NM}^{*}$ \\
\hline FAME content, $\max$ & Vol\% & 5 & $\mathrm{NM}^{*}$ \\
\hline
\end{tabular}

TABLE 6: Properties of the EN590 reference fuel used in the current study.

\begin{tabular}{|c|c|c|c|}
\hline Property & Unit & EN590: 2009 specification & EN590 \\
\hline Cetane Number & & $51(\min )$ & 57 \\
\hline Density at $15^{\circ} \mathrm{C}$ & $\mathrm{kg} / \mathrm{m}^{3}$ & $820-845$ & 833 \\
\hline Flash Point & ${ }^{\circ} \mathrm{C}$ & $55(\min )$ & 84 \\
\hline Viscosity at $40^{\circ} \mathrm{C}$ & $\mathrm{mm}^{2} / \mathrm{s}$ & $2.0-4.5$ & 2.79 \\
\hline Lubricity, corrected wear scar diameter at $60^{\circ} \mathrm{C}$ & micron & $460(\max )$ & 327 \\
\hline FAME content & vol\% & $7(\max )$ & 0 \\
\hline Total Aromatics Content & $\%(\mathrm{v} / \mathrm{v})$ & $\mathrm{NS}^{*}$ & 22.80 \\
\hline Sulphur content & ppm & $10(\max )$ & $<1$ \\
\hline Carbon residue (on $10 \%$ distillation residue) & mass $\%$ & $0.3(\max )$ & 0.02 \\
\hline Ash content & mass $\%$ & $0.01(\max )$ & $<0.01$ \\
\hline Water Content & ppm & $200(\max )$ & 44 \\
\hline Total contamination & ppm & $24(\max )$ & 0.60 \\
\hline Copper strip corrosion $\left(3 \mathrm{~h}\right.$ at $\left.50^{\circ} \mathrm{C}\right)$ & rating & Class 1 & la \\
\hline Oxidation stability & $\mathrm{h}$ & $20(\min )$ & $>20$ \\
\hline PAH's & $\%(\mathrm{~m} / \mathrm{m})$ & 8 & $\mathrm{NM}^{*}$ \\
\hline $\mathrm{CP}$ & ${ }^{\circ} \mathrm{C}$ & -10 to -34 & -22 \\
\hline CFPP & ${ }^{\circ} \mathrm{C}$ & 5 to -44 & -20 \\
\hline $\mathrm{PP}$ & ${ }^{\circ} \mathrm{C}$ & NS* & -27 \\
\hline Distillation 95\% (v/v recovered at) as measured by ASTM D86 & ${ }^{\circ} \mathrm{C}$ & 360 & 348 \\
\hline
\end{tabular}

${ }^{*}$ NS: no specification available.

${ }^{*} \mathrm{NM}$ : not measured.

\section{Results}

In the next sections, the performance of the binary blends of RME (low and high stability) with two GTL diesel fuels, EN590 diesel and US 2-D, diesel is discussed. As the same FAME samples (low and high stability RME) were used for comparable samples, the results should give a good indication of the relative performance of the base fuels in terms of fuel stability.

\subsection{Stability Performance of the Binary Blends}

4.1.1. Rancimat Results of the Low Stability FAME Blends. In Figure 1, the stability results of the low stability FAME blends in the Rancimat test are shown.

Several interesting trends can be seen in the results. Firstly, there is a drastic decrease in the stability of the blends in the range of $2-10 \%$ FAME, followed by a generally slower decrease in blend stability between $10 \%$ and 20\% FAME 
TABLE 7: Properties of the GTL diesel fuel in comparison with the recently accepted CEN TS 15940: 2012 specifications.

\begin{tabular}{|c|c|c|c|c|}
\hline Property & Unit & $\begin{array}{c}\text { Paraffinic diesel specification } \\
\text { (Class A) }\end{array}$ & Summer GTL diesel & Winter GTL diesel \\
\hline Cetane Number & & $70(\mathrm{~min})$ & 80 & 71 \\
\hline Density at $15^{\circ} \mathrm{C}$ & $\mathrm{kg} / \mathrm{m}^{3}$ & $765-800$ & 766 & 773 \\
\hline Flash Point & ${ }^{\circ} \mathrm{C}$ & $55(\min )$ & 58 & 63 \\
\hline Viscosity at $40^{\circ} \mathrm{C}$ & $\mathrm{mm}^{2} / \mathrm{s}$ & $2.00-4.50$ & 2.19 & 2.30 \\
\hline Lubricity, corrected wear scar diameter at $60^{\circ} \mathrm{C}$ & micron & $460(\max )$ & $367^{\#}$ & $548^{* *}$ \\
\hline FAME content & vol\% & $7 \% \max$ & 0 & 0 \\
\hline Total Aromatics Content & $\%(\mathrm{v} / \mathrm{v})$ & $1.0(\max )$ & $<0.1$ & 0.01 \\
\hline Sulphur content & ppm & $5(\max )$ & $<1$ & 1.5 \\
\hline Carbon residue (on $10 \%$ distillation residue) & mass $\%$ & $0.3(\max )$ & 0.06 & 0.04 \\
\hline Ash content & mass $\%$ & $0.01(\max )$ & $<0.01$ & $<0.01$ \\
\hline Water Content & ppm & $200(\max )$ & 50 & ND \\
\hline Total contamination & ppm & $24(\max )$ & 2 & 1 \\
\hline Copper strip corrosion $\left(3 \mathrm{~h}\right.$ at $\left.50^{\circ} \mathrm{C}\right)$ & rating & Class 1 & $1 b$ & $1 b$ \\
\hline Oxidation stability & $\mathrm{h}$ & $20(\min )$ & $>20$ & \\
\hline $\mathrm{CP}$ & ${ }^{\circ} \mathrm{C}$ & EN590 & -7 & $>20$ \\
\hline CFPP & ${ }^{\circ} \mathrm{C}$ & EN590 & -9 & -45 \\
\hline $\mathrm{PP}$ & ${ }^{\circ} \mathrm{C}$ & NS* & -14 & -45 \\
\hline Acid number & $\mathrm{gKOH} / \mathrm{g}$ & $\mathrm{NS}^{*}$ & 0.01 & 0.001 \\
\hline Distillation (v/v recovered at $95 \%)$ & ${ }^{\circ} \mathrm{C}$ & $360(\max )$ & 347 & 353.2 \\
\hline
\end{tabular}

*NS: no specification available.

${ }^{*} \mathrm{NM}$ : not measured.

${ }^{* *}$ No lubricity additive added.

\#Additised with lubricity improver additive.

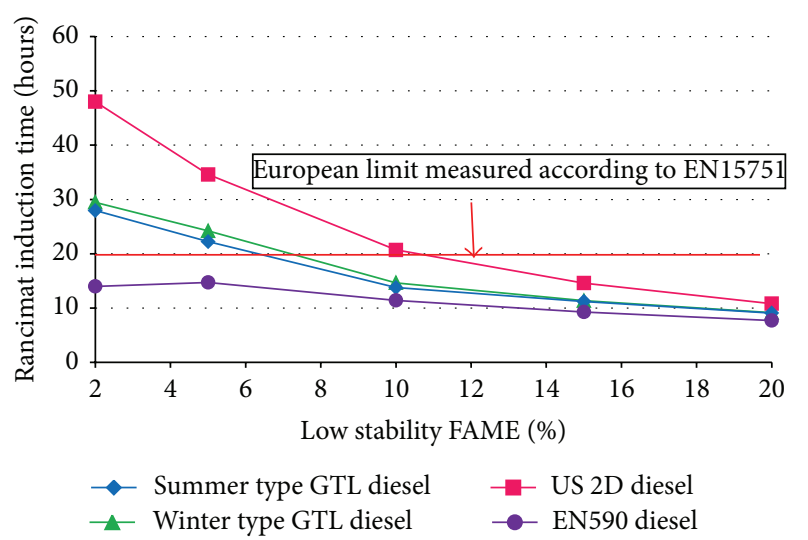

FIGURE 1: Effect of increasing concentration of biodiesel on the Rancimat stability of the low stability FAME blends.

content. Generally, the stability of FAME is significantly lower than that of a petroleum-derived diesel $[19,20]$. The mechanism of neat FAME degradation is generally well understood. It was also extensively shown in literature that the addition of FAME to a petroleum-derived or an FT derived diesel would result in a significant decrease in the stability of the fuel blend (in comparison with the neat petroleum-derived or FT-derived fuel [23]. The mechanism of the degradation of FAME/paraffinic diesel blends is, however, not well understood.
It is evident that the US 2-D diesel blends were more stable than the other low stability FAME/diesel blends. It was not possible to determine whether this fuel contained any antioxidants. It was considered to be outside the scope of the current study to determine the levels of any antioxidants in the fuel. This aspect may form part of a future investigation. The reason for this stability could also not be found in the full specification analyses of the fuels. Given that the stability of a fuel is typically determined by trace components, it is unlikely that this will be evident from the bulk properties of the fuel.

The two GTL diesel samples (neat and containing FAME) lay between the US 2-D blends and the EN590 blends. The EN590 diesel blends were the lowest in stability, but, at high FAME contents, the difference is reduced significantly, approaching the Rancimat induction time of 3.62 hours for the neat FAME.

4.1.2. Rancimat Results of the High Stability FAME Blends. In Figure 2, the Rancimat stabilities of the high stability FAME blends are shown.

Similar to the low stability FAME results, the EN590 diesel blends had the lowest Rancimat stability, followed by the "summer type" GTL diesel blends. Similar to the low stability FAME blends, the difference in stability between the different base fuel blends was significantly diminished at higher FAME concentrations, and, at 20\% FAME, the differences appeared negligible compared to higher FAME concentrations. At $20 \%$ FAME addition, the stability of the blends is still 
TABLE 8: Properties of the RME biodiesel used in the current study.

\begin{tabular}{|c|c|c|c|}
\hline Property & Unit & EN 14214 specification & RME \\
\hline Cetane number & & $51 \mathrm{~min}$ & 60.6 \\
\hline Density at $15^{\circ} \mathrm{C}$ & $\mathrm{kg} / \mathrm{m}^{3}$ & $860-900$ & 879 \\
\hline Flash Point & ${ }^{\circ} \mathrm{C}$ & $120(\min )$ & 161 \\
\hline Viscosity at $40^{\circ} \mathrm{C}$ & $\mathrm{mm}^{2} / \mathrm{s}$ & $3.5-5.0$ & 4.53 \\
\hline Lubricity, corrected wear scar diameter at $60^{\circ} \mathrm{C}$ & micron & & $\mathrm{NM}^{*}$ \\
\hline FAME content & $\%(\mathrm{~mol} / \mathrm{mol})$ & 96.5 (min) & 100.0 \\
\hline Sulphur content & $\mathrm{mg} / \mathrm{kg}$ & $10.0 \max$ & 2 \\
\hline Carbon residue (on 10\% distillation residue) & $\%(\mathrm{~mol} / \mathrm{mol})$ & $0.30 \max$ & 0.09 \\
\hline Sulfated ash content & $\%(\mathrm{~mol} / \mathrm{mol})$ & $0.02 \max$ & $<0.01$ \\
\hline Water content & $\mathrm{mg} / \mathrm{kg}$ & $500 \max$ & 158 \\
\hline Total contamination & $\mathrm{mg} / \mathrm{kg}$ & $24 \max$ & 16.5 \\
\hline Copper strip corrosion $\left(3 \mathrm{~h}\right.$ at $\left.50^{\circ} \mathrm{C}\right)$ & rating & 1 & $1 b$ \\
\hline Oxidation stability, $110^{\circ} \mathrm{C}$ & $\mathrm{h}$ & $6.0 \mathrm{~min}$ & 6.64 \\
\hline $\mathrm{CP}$ & ${ }^{\circ} \mathrm{C}$ & & -4 \\
\hline CFPP & ${ }^{\circ} \mathrm{C}$ & & -13 \\
\hline $\mathrm{PP}$ & ${ }^{\circ} \mathrm{C}$ & & -11 \\
\hline Acid value & $\mathrm{mg} \mathrm{KOH} / \mathrm{g}$ & $0.50 \max$ & 0.12 \\
\hline$I$ value (Br number) & $\mathrm{g} \mathrm{Br} / 100 \mathrm{~g}$ & $120 \max$ & 58 \\
\hline Group I metals $(\mathrm{Na}+\mathrm{K})$ & & $5 \max$ & $<1$ \\
\hline Group II metals ( $\mathrm{Ca}+\mathrm{Mg})$ & & $5 \max$ & $<1$ \\
\hline Linolenic acid content & $\%(\mathrm{~m} / \mathrm{m})$ & $12.0 \max$ & 8.30 \\
\hline Methanol content & $\%(\mathrm{~m} / \mathrm{m})$ & $0.20 \max$ & 0.02 \\
\hline Monoglyceride content & $\%(\mathrm{~m} / \mathrm{m})$ & $0.80 \max$ & 0.53 \\
\hline Diglyceride content & $\%(\mathrm{~m} / \mathrm{m})$ & $0.20 \max$ & 0.14 \\
\hline Triglyceride content & $\%(\mathrm{~m} / \mathrm{m})$ & $0.20 \max$ & 0.08 \\
\hline Free glycerol & $\%(\mathrm{~m} / \mathrm{m})$ & $0.020 \max$ & 0.01 \\
\hline Total glycerol & $\%(\mathrm{~m} / \mathrm{m})$ & $0.25 \max$ & 0.17 \\
\hline
\end{tabular}

${ }^{*} \mathrm{NM}$ : not measured.

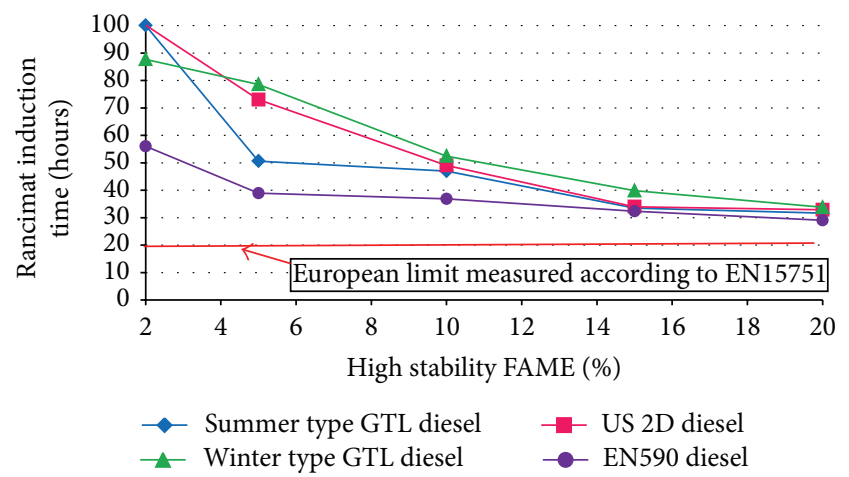

FIGURE 2: Effect of increasing concentration of biodiesel on the Rancimat stability of the high stability FAME blends.

significantly above the stability of the neat FAME (8.8 hours), showing that the base fuels do contribute to the stability of the blend.

4.1.3. PetroOxy Results of the Blends of Low Stability FAME Blends. Several authors have reported the use of the PetroOxy test to evaluate the stability of neat FAME [30-33]. The

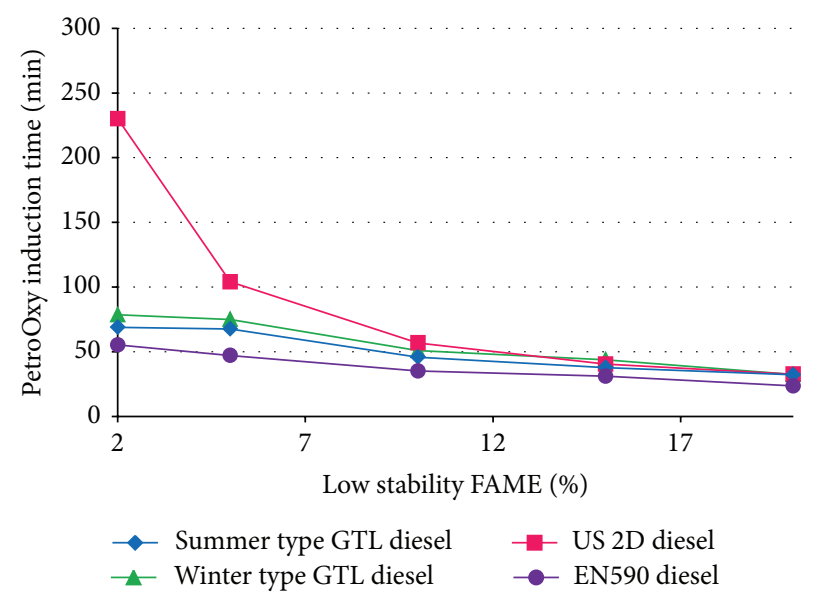

FIgURE 3: PetroOxy stability results of the low stability FAME blends.

PetroOxy results of the diesel fuels, blended with the low stability FAME, are shown in Figure 3.

There are some similarities between the trends obtained from the PetroOxy and the Rancimat results. One of the main 
TABLE 9: Evaluation matrix for the evaluation of the stability of FAME/petroleum-derived and GTL diesel blends.

\begin{tabular}{|c|c|c|c|c|c|c|}
\hline Run & A: summer type GTL diesel & B: winter type GTL diesel & C: EN590 & D: US-2D & E: Bio & Bio type \\
\hline 1 & 0 & 0 & 100 & 0 & 0 & RME high \\
\hline 2 & 0 & 20 & 0 & 80 & 0 & RME high \\
\hline 3 & 50 & 40 & 0 & 0 & 10 & RME low \\
\hline 4 & 0 & 0 & 0 & 90 & 10 & RME high \\
\hline 5 & 0 & 0 & 0 & 100 & 0 & RME high \\
\hline 6 & 50 & 0 & 30 & 20 & 0 & RME low \\
\hline 7 & 0 & 20 & 40 & 30 & 10 & RME low \\
\hline 8 & 50 & 0 & 50 & 0 & 0 & RME low \\
\hline 9 & 100 & 0 & 0 & 0 & 0 & RME high \\
\hline 10 & 0 & 100 & 0 & 0 & 0 & RME low \\
\hline 11 & 50 & 0 & 0 & 40 & 10 & RME high \\
\hline 12 & 40 & 40 & 20 & 0 & 0 & RME high \\
\hline 13 & 0 & 50 & 10 & 30 & 10 & RME low \\
\hline 14 & 0 & 50 & 50 & 0 & 0 & RME low \\
\hline 15 & 10 & 50 & 0 & 20 & 20 & RME low \\
\hline 16 & 60 & 0 & 30 & 0 & 10 & RME high \\
\hline 17 & 0 & 0 & 80 & 0 & 20 & RME low \\
\hline 18 & 0 & 0 & 100 & 0 & 0 & RME high \\
\hline 19 & 45 & 0 & 0 & 45 & 10 & RME low \\
\hline 20 & 0 & 0 & 80 & 0 & 20 & RME high \\
\hline 21 & 50 & 50 & 0 & 0 & 0 & RME low \\
\hline 22 & 100 & 0 & 0 & 0 & 0 & RME high \\
\hline 23 & 16 & 10 & 16 & 58 & 0 & RME low \\
\hline 24 & 0 & 50 & 50 & 0 & 0 & RME low \\
\hline 25 & 10 & 0 & 50 & 40 & 0 & RME low \\
\hline 26 & 40 & 20 & 20 & 0 & 20 & RME high \\
\hline 27 & 0 & 0 & 50 & 50 & 0 & RME high \\
\hline 28 & 80 & 0 & 0 & 0 & 20 & RME high \\
\hline 29 & 10 & 80 & 0 & 10 & 0 & RME low \\
\hline 30 & 0 & 40 & 0 & 60 & 0 & RME high \\
\hline 31 & 0 & 80 & 0 & 0 & 20 & RME high \\
\hline 32 & 0 & 0 & 0 & 80 & 20 & RME high \\
\hline 33 & 16 & 6 & 0 & 58 & 20 & RME low \\
\hline
\end{tabular}

observations is the higher initial stability for the US 2-D diesel blends. This higher initial value is, however, significantly reduced by the addition of biodiesel. At 10\% FAME addition, a significant portion of this benefit is lost, and it reduces further at higher FAME contents. The incremental reduction in stability with an increase in FAME concentration was evident in all the fuels that were evaluated. As expected, it therefore appears that the stability of the base fuel dominates at low FAME contents $(<10 \%)$, while at higher FAME contents $(>10 \%)$ the FAME dominates the stability performance of the blend.

4.1.4. PetroOxy Results of the Blends of High Stability FAME Blends. In Figure 4, the PetroOxy stability of the high stability FAME blends is shown.

Interestingly, the addition of 5\% high stability FAME resulted in an improvement in the stability of the FT diesel blends (compared to the neat fuels. see data in Table 11). At

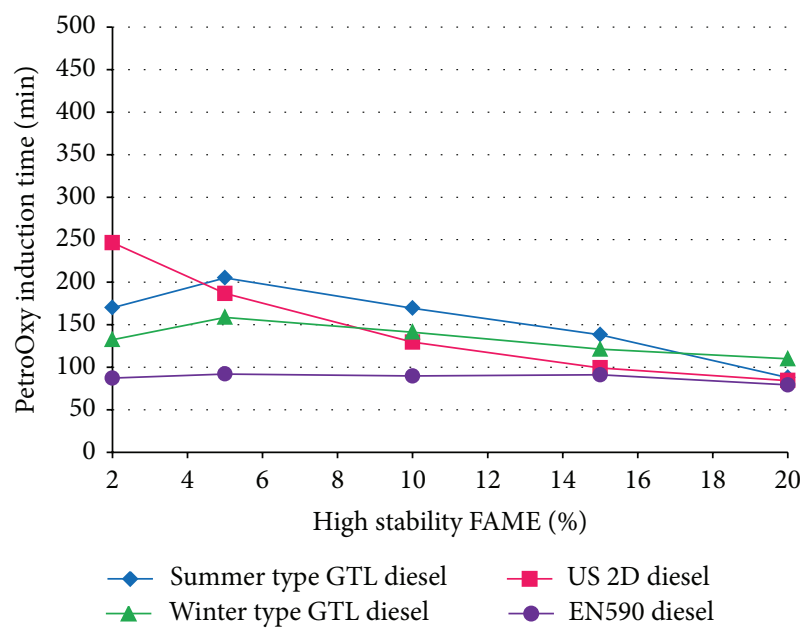

Figure 4: PetroOxy results of the high stability FAME blends. 
TABLE 10: ASTM D2274 results of the samples evaluated in this study.

\begin{tabular}{|c|c|c|c|c|c|}
\hline High stability FAME & $\%$ FAME & $\begin{array}{c}\text { ASTM D2274 } \\
(\mathrm{mg} / 100 \mathrm{~mL})\end{array}$ & Low stability FAME & $\%$ FAME & $\begin{array}{c}\text { ASTM D2274 } \\
(\mathrm{mg} / 100 \mathrm{~mL}) \\
\end{array}$ \\
\hline \multicolumn{6}{|c|}{ Summer type GTL diesel blends } \\
\hline Summer type GTL diesel & 0 & 0.4 & Summer type GTL diesel & 0 & 0.4 \\
\hline Summer type GTL + 2\% RME & 2 & 0.2 & Summer type GTL + 2\% RME & 2 & 0.2 \\
\hline Summer type GTL + 5\% RME & 5 & 0.3 & Summer type GTL + 5\% RME & 5 & 0.5 \\
\hline Summer type GTL + 10\% RME & 10 & 0.3 & Summer type GTL + 10\% RME & 10 & 0.3 \\
\hline Summer type GTL + 15\% RME & 15 & 0.2 & Summer type GTL + 15\% RME & 15 & 0.4 \\
\hline Summer type GTL + 20\% RME & 20 & 0.2 & Summer type GTL + 20\% RME & 20 & 0.3 \\
\hline \multicolumn{6}{|c|}{ US 2D diesel } \\
\hline US 2D diesel & 0 & 0.2 & US 2D diesel & 0 & 0.2 \\
\hline US $2 \mathrm{D}$ diesel + $2 \% \mathrm{RME}$ & 2 & 0.2 & US 2D diesel + 2\% RME & 2 & 0.2 \\
\hline US 2D diesel + 5\% RME & 5 & 0.5 & US 2D diesel + 5\% RME & 5 & 1.5 \\
\hline US 2D diesel + 10\% RME & 10 & 0.3 & US 2D diesel + 10\% RME & 10 & 0.3 \\
\hline US 2D diesel + 15\% RME & 15 & 0.5 & US 2D diesel + 15\% RME & 15 & 0.8 \\
\hline US 2D diesel + 20\% RME & 20 & 0.5 & US 2D diesel + 20\% RME & 20 & 1.5 \\
\hline \multicolumn{6}{|c|}{ Winter type GTL diesel } \\
\hline Winter type GTL diesel & 0 & 0.4 & Winter type GTL diesel & 0 & 0.4 \\
\hline Winter type GTL + $2 \%$ RME & 2 & 0.3 & Winter type GTL + 2\% RME & 2 & 0.3 \\
\hline Winter type GTL + 5\% RME & 5 & 0.5 & Winter type GTL + 5\% RME & 5 & 0.4 \\
\hline Winter type GTL + 10\% RME & 10 & 0.3 & Winter type GTL + 10\% RME & 10 & 0.2 \\
\hline Winter type GTL + 15\% RME & 15 & 0.5 & Winter type GTL + 15\% RME & 15 & 0.3 \\
\hline Winter type GTL + 20\% RME & 20 & 0.3 & Winter type GTL + 20\% RME & 20 & 0.7 \\
\hline \multicolumn{6}{|c|}{ EN590 diesel } \\
\hline EN590 & 0 & 0.3 & EN590 & 0 & 0.3 \\
\hline EN590 + 2\% RME & 2 & 0.3 & EN590 + 2\% RME & 2 & 0.2 \\
\hline EN590 + 5\% RME & 5 & 0.3 & EN590 + 5\% RME & 5 & 0.4 \\
\hline EN590 + 10\% RME & 10 & 0.9 & EN590 + 10\% RME & 10 & 0.4 \\
\hline EN590 + 15\% RME & 15 & 0.9 & EN590 + 15\% RME & 15 & 0.4 \\
\hline EN590 + 20\% RME & 20 & 0.2 & $\mathrm{EN} 590+20 \% \mathrm{RME}$ & 20 & 0.4 \\
\hline
\end{tabular}

higher FAME concentrations in the FT diesel blends, the stability of the FAME-containing blends decreases, in line with expectations. It is speculated that this is due to the antioxidant present in the FAME, which shows a synergistic effect with the GTL diesel (stable but containing no antioxidants). Interestingly, the results appear to converge less at higher FAME contents than the low stability FAME blends.

4.1.5. ASTM D2274 Stability of the FAME Blends. The ASTM D2274 results are provided in Table 10. The ASTM D2274 test was less sensitive to the FAME/GTL diesel and FAME/petroleum-derived diesel samples. This is speculated to be due to the oxidised FAME, which acts as an effective solvent, dissolving the deposits.

Hartikka et al. [5] used a slightly different test (ASTM D5304) to assess the stability of the soy biodiesel/FT diesel blends. The principles, however, are similar. It was therefore surprising to see that the poor stability results obtained by Mushrush et al. on FAME/FT diesel blends were not observed in any of the samples, evaluated in the current study. The industry consensus is that this test is most likely not relevant to FAME-containing fuels and that Rancimat is the preferred method for blends containing more than 2\% FAME [22]. ASTM D5304 analyses were carried out on a few selected FAME/GTL diesel and FAME/EN590 diesel blends. The results are presented in Table 4 .

The results indicate that although there was a slight increase in the amount of deposit at 5\% FAME in GTL diesel, this was relatively insignificant. It is also evident that the results on the FAME/GTL diesel blends showed an insignificant increase compared to the results quoted in the publication by Mushrush et al.

4.2. Correlation between the Rancimat and PetroOxy Results of the Binary Blends. The Rancimat method is significantly more difficult to execute than the PetroOxy test, given the consumables (glass tubes and seals) and time required for sample preparation and the actual analysis. It would therefore be advantageous to replace the Rancimat with the PetroOxy method, if possible. The East Asia working research group carried out Rancimat and PetroOxy measurements on neat biodiesel fuels [30]. They reported a good correlation between 
TABLE 11: PetroOxy results of the samples evaluated in this study.

\begin{tabular}{|c|c|c|c|c|c|}
\hline High stability FAME & $\%$ FAME & $\begin{array}{c}\text { PetroOxy } \\
\text { induction time } \\
(\min )\end{array}$ & Low stability FAME & $\%$ FAME & $\begin{array}{c}\text { PetroOxy } \\
\text { induction time } \\
(\min )\end{array}$ \\
\hline \multicolumn{6}{|c|}{ Summer type GTL diesel blends } \\
\hline Summer type GTL diesel & 0 & 79.35 & Summer type GTL diesel & 0 & 79.35 \\
\hline Summer type GTL + 2\% RME & 2 & 170 & Summer type GTL + 2\% RME & 2 & 68.9 \\
\hline Summer type GTL + 5\% RME & 5 & 205.13 & Summer type GTL + 5\% RME & 5 & 67.58 \\
\hline Summer type GTL + 10\% RME & 10 & 169.5 & Summer type GTL + 10\% RME & 10 & 45.78 \\
\hline Summer type GTL + 15\% RME & 15 & 138.18 & Summer type GTL + 15\% RME & 15 & 37.71 \\
\hline Summer type GTL + 20\% RME & 20 & 87.91 & Summer type GTL + 20\% RME & 20 & 32.11 \\
\hline \multicolumn{6}{|c|}{ US 2-D diesel } \\
\hline US 2-D diesel & 0 & 785.23 & US 2-D diesel & 0 & 785.23 \\
\hline US 2-D diesel + 2\% RME & 2 & 246.41 & US 2-D diesel + 2\% RME & 2 & 230.13 \\
\hline US 2-D diesel + 5\% RME & 5 & 186.68 & US 2-D diesel + 5\% RME & 5 & 103.96 \\
\hline US 2-D diesel + 10\% RME & 10 & 129.48 & US 2-D diesel + 10\% RME & 10 & 56.81 \\
\hline US 2-D diesel + 15\% RME & 15 & 99.2 & US 2-D diesel + 15\% RME & 15 & 40.35 \\
\hline US 2-D diesel + 20\% RME & 20 & 84.31 & US 2-D diesel + 20\% RME & 20 & 32.6 \\
\hline \multicolumn{6}{|c|}{ Winter type GTL diesel } \\
\hline Winter type GTL diesel & 0 & 79.35 & Winter type GTL diesel & 0 & 79.35 \\
\hline Winter type GTL diesel + 2\% RME & 2 & 132.36 & Winter type GTL + $2 \%$ RME & 2 & 58.48 \\
\hline Winter type GTL diesel + 5\% RME & 5 & 158.71 & Winter type GTL + 5\% RME & 5 & 74.9 \\
\hline Winter type GTL diesel + 10\% RME & 10 & 141.21 & Winter type GTL + 10\% RME & 10 & 50.8 \\
\hline Winter type GTL diesel + 15\% RME & 15 & 121.16 & Winter type GTL + 15\% RME & 15 & 43.75 \\
\hline Winter type GTL diesel + 20\% RME & 20 & 109.85 & Winter type GTL + 20\% RME & 20 & 32.35 \\
\hline \multicolumn{6}{|c|}{ EN590 diesel } \\
\hline EN590 & 0 & 83.63 & EN590 & 0 & 83.63 \\
\hline $\mathrm{EN} 590+2 \% \mathrm{RME}$ & & & EN590 + 2\% RME & & 55.2 \\
\hline EN590 + 5\% RME & 5 & 92 & EN590 + 5\% RME & 5 & 47.08 \\
\hline EN590 + 10\% RME & 10 & 89.73 & EN590 + 10\% RME & 10 & 35.05 \\
\hline EN590 + 15\% RME & 15 & 91.03 & EN590 + 15\% RME & 15 & 31.01 \\
\hline EN590 + 20\% RME & 20 & 79.18 & EN590 + 20\% RME & 20 & 23.53 \\
\hline RME high stability & & $41.51 \mathrm{~min}$ & & & \\
\hline RME low stability & & $34.55 \mathrm{~min}$ & & & \\
\hline
\end{tabular}

the Rancimat test and the PetroOxy test. It should, however, be stressed that these analyses were carried out on neat biodiesel fuels only.

In the current study, the correlation between these two techniques was also investigated. In contrast to the East Asia workgroup's study, neat and blended FAME samples were included. In Figure 5, the correlation between the two techniques is shown for the FAME/diesel blends.

It can be seen that, in any specific series, there appears to be a linear relationship between the PetroOxy and the Rancimat results. However, this relationship seems to be highly dependent on the base fuel. Another aspect that was observed for the FAME/GTL diesel blends was the increase in the stability of the blends, containing 5\% FAME. This effect was not seen in the Rancimat results. It can therefore be concluded that the correlation appears to be highly fuel dependent implying that, in a given series, for example, for a specific GTL

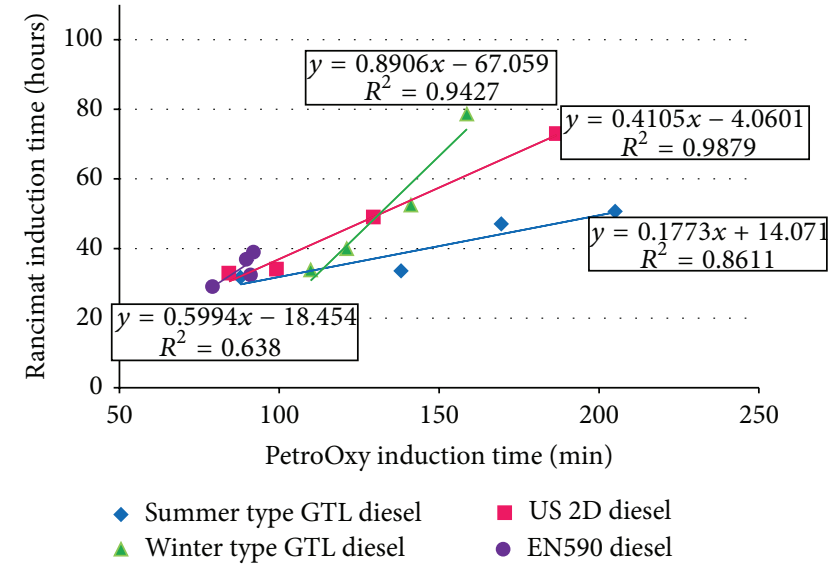

FIgURE 5: Correlation between the PetroOxy induction time and the Rancimat induction time for the high stability FAME blends. 
diesel, blended with FAME it may be possible to substitute the Rancimat for the PetroOxy technique, but the one technique cannot, in general, be substituted for the other. A recent study indicated that, for neat FAME samples, a linear correlation exists between the PetroOxy and Rancimat methods, potentially enabling the PetroOxy to replace the more time-consuming Rancimat method [31].

4.3. Correlation between the PetroOxy and ASTM D2274 Results of the Binary Blends. In Figure 6, the correlation between the Rancimat and the ASTM D2274 results are shown.

Based on visual assessment and determination of the $R^{2}$ values, there appears to be no relationship between the Rancimat and the ASTM D2274 results. Reference [5] indicated that the correlation between EN ISO 12205 (equivalent to ASTM D2274) and the PetroOxy test is weak for HVO blends, with the PetroOxy test being able to distinguish better between fuels having different stabilities. Interestingly, apart from two "outliers," the data points all lie in a very small envelope (despite the clear absence of some kind of correlation and probably due to the insensitivity of the method as stated below).

\section{Results of the Statistical Evaluation}

The blending properties of the five fuel components and the effect of biodiesel type were evaluated statistically by means of regression analysis methods. Valid "mixture by process" models have been identified for the PetroOxy results $\left(R^{2}\right.$ of $0.86)$ as well as for the Rancimat results $\left(R^{2}\right.$ of 0.82$)$. No statistical analysis was carried out on the ASTM D2274 as the method proved to be insensitive to changes in the FAME content of the fuel blends.

The PetroOxy and Rancimat models are interpreted graphically using response trace plots. A trace plot shows how each component influences the response relative to the reference blend. In this study, the reference blend is the centroid of the design vertices. The total effect of a fuel component will depend on both the range of the fuel component and the steepness of its response trace. The total effect is defined as the difference in the response between the effect direction point at which the component is at its upper bound and the effect direction point at which the component is at its lower bound.

Components with approximately horizontal response traces, with respect to the reference blend, have virtually no effect on the response and components with similar response traces will have similar effects on the response of the reference blend.

Results from the statistical evaluation are discussed in more detail below.

\subsection{PetroOxy Results}

5.1.1. Statistical Analysis of the PetroOxy Results of the Low and High Stability FAME Blends. In Figure 7, the trace plots of the PetroOxy results of low and high stability FAME measurements are shown. The full 33 sample set was used for the correlation, as the PetroOxy test is applicable to any B0B100 blend.

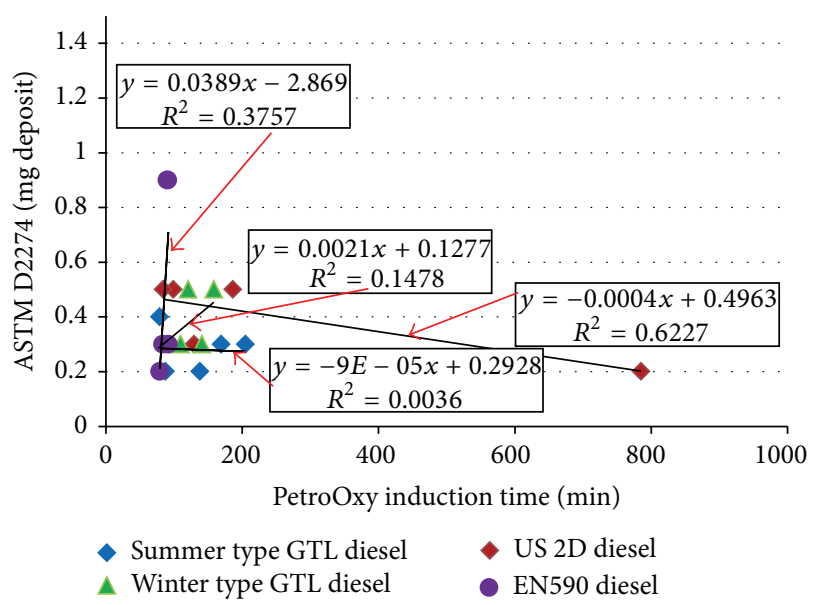

FIGURE 6: Correlation of the Rancimat and ASTM D2274 stabilities of the diesel fuels, blended with a high stability RME biodiesel.

The statistical analyses of the PetroOxy results on the low and high stability FAME samples showed similar trends, with FAME being the most important factor determining the stability of the blend, with an increasing FAME content resulting in a decrease in the stability. It is evident that the US 2-D diesel (highly stable) also had a significant positive influence on the stability of the blends.

Components with approximately horizontal response traces, with respect to the reference blend, have virtually no effect on the response, such as the FT diesel fuels and the EN590, see Figure 7(a) (Low RME) and Figure 7(b) (High RME). Thus, the two most influential, components to PetroOxy is firstly US 2-D diesel, which increased stability and secondly FAME concentration which caused a decrease in stability. The high stability influence of the US 2-D diesel was, however, only significant at higher concentrations. The base fuel stability was significantly reduced as the FAME content was increased in the blend at higher FAME contents. The FT diesel fuels and the EN590 diesel fuel showed similar trends, having a very small influence on the stability of the blend.

5.2. Rancimat Results. The trace plot of the Rancimat model (looking at the average of low and high stability FAME) is given in Figure 8.

Similar trends are observed for the four non-FAME containing fuels. The plot shows the Rancimat values to increase with high FT diesel fuels, high EN590, and high US 2D and low FAME concentrations. In line with expectations, FAME content appears to be the largest influencing variable on stability.

This study showed that the addition of FAME to any fuel, EN590, US 2D, and/or GTL diesel, decreases the stability of the final blend according to the Rancimat test. The statistical evaluation has further confirmed that the stability of GTL diesel is affected in the same manner as petroleum-derived diesel upon addition of FAME. 


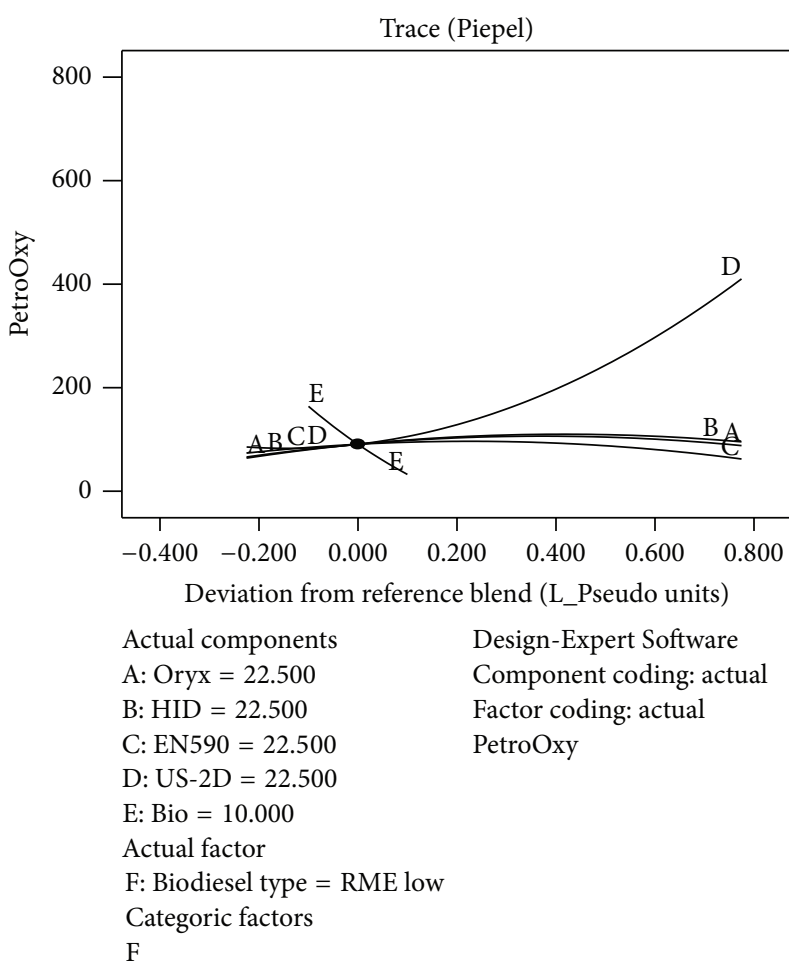

(a)

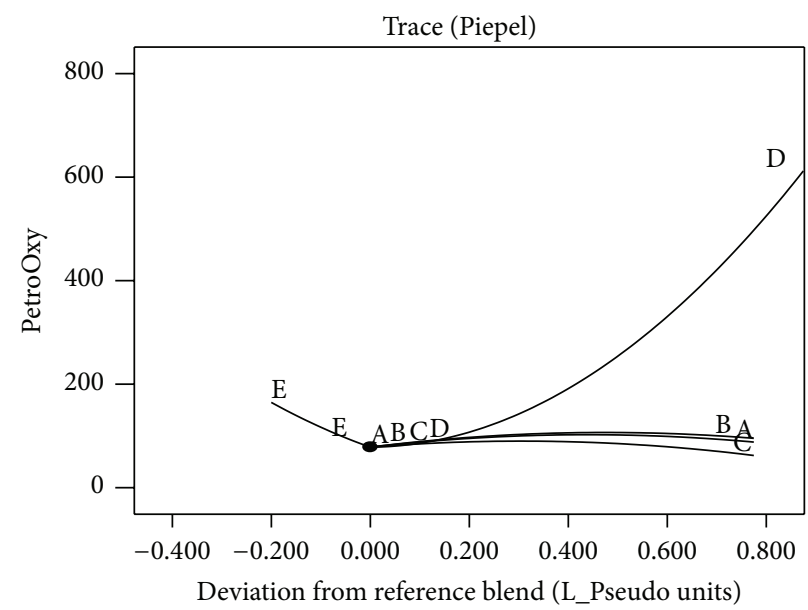

$\begin{array}{ll}\text { Actual components } & \begin{array}{l}\text { Design-Expert Software } \\ \text { Component coding: actual }\end{array} \\ \text { A: Oryx }=22.500 & \text { Factor coding: actual } \\ \text { B: } \text { HID }=22.500 & \text { PetroOxy } \\ \text { C: EN590 }=22.500 & \\ \text { D: US-2D }=12.500 & \\ \text { E: Bio }=20.000 & \\ \text { Actual factor } & \\ \text { F: Biodiesel type }=\text { RME high } & \\ \text { Categoric factors } & \\ \text { F } & \end{array}$

(b)

FIgURE 7: Statistical analysis of the PetroOxy results of (a) the low stability and (b) high stability FAME blends*. (A = "summer type" GTL diesel, B = "winter type" GTL diesel, C = EN590 diesel, D = US 2-D content), and E = FAME content.

5.3. ASTM D2274 Results. No statistical analysis was carried out on the ASTM D2274 results. Given that the repeatability of the method is $3-7 \mathrm{mg} / 100 \mathrm{~mL}$ and the range of the results is between 0 and $1 \mathrm{mg} / 100 \mathrm{~mL}$, the method was shown to be insensitive to changes in the addition of FAME over the blend range tested.

\section{Conclusions}

The diesel landscape has changed significantly with the incorporation of several alternative fuels in the international diesel fuel pool. Paraffinic diesels have several advantages over conventional diesels, including zero sulphur content, low levels of aromatics, and high cetane numbers. One of the critical aspects to ensure that a diesel maintains its properties during use is the stability of the fuel. Several stability measurement techniques exist in the petroleum industry, including ASTM D2274, the PetroOxy test, and the Rancimat test.

Although FT diesel (in particular GTL diesel) is generally known to be highly stable, contrasting information exists in open literature regarding the stability of FT diesel in blends with FAME. In order to study the performance of FAME/GTL diesel blends, the current study focused on the stability performance of blends of biodiesel (rapeseed methyl ester (RME)) with GTL diesel. The stabilities of these blends were compared with the stability of biodiesel/petroleum-derived diesel blends. Two RME biodiesels of different stabilities were evaluated in blends with petroleum-derived diesel and GTL diesel, respectively. It was observed that the Rancimat and the PetroOxy tests are sensitive to the addition of FAME in paraffinic fuels. The FAME/GTL diesel appeared to perform similar to the FAME/petroleum-derived diesel blends for the fuels studied. The statistical approach, where binary, ternary, and quaternary interactions were studied, showed that the base fuels reacted very similarly to the addition of FAME. The exception was the performance of the high stability FAME/GTL diesel blends, where an unexpected increase in stability was found in the PetroOxy test. This was speculated to be due to a synergistic interaction between the antioxidant in the FAME and the GTL diesel. It was also shown that the Rancimat and PetroOxy correlate when there is a commonality in the base fuel but cannot be used without a calibration on the particular base fuel.

This study did not focus on determining the level of antioxidants in the respective fuels and the remaining antioxidant levels in the biodiesel. This was considered to be outside the current scope and may form part of a future investigation.

Overall, the FAME/GTL diesel blends performed in a similar manner to the reference fuels evaluated in this study. No evidence was found to support prior work by Mushrush et al. that FAME/paraffinic diesel blends may result in excessive deposit formation in laboratory oxidative tests, in this case ASTM D2274 and ASTM D5304 (on selected samples) as found by Mushrush et al. We, however, acknowledge that 


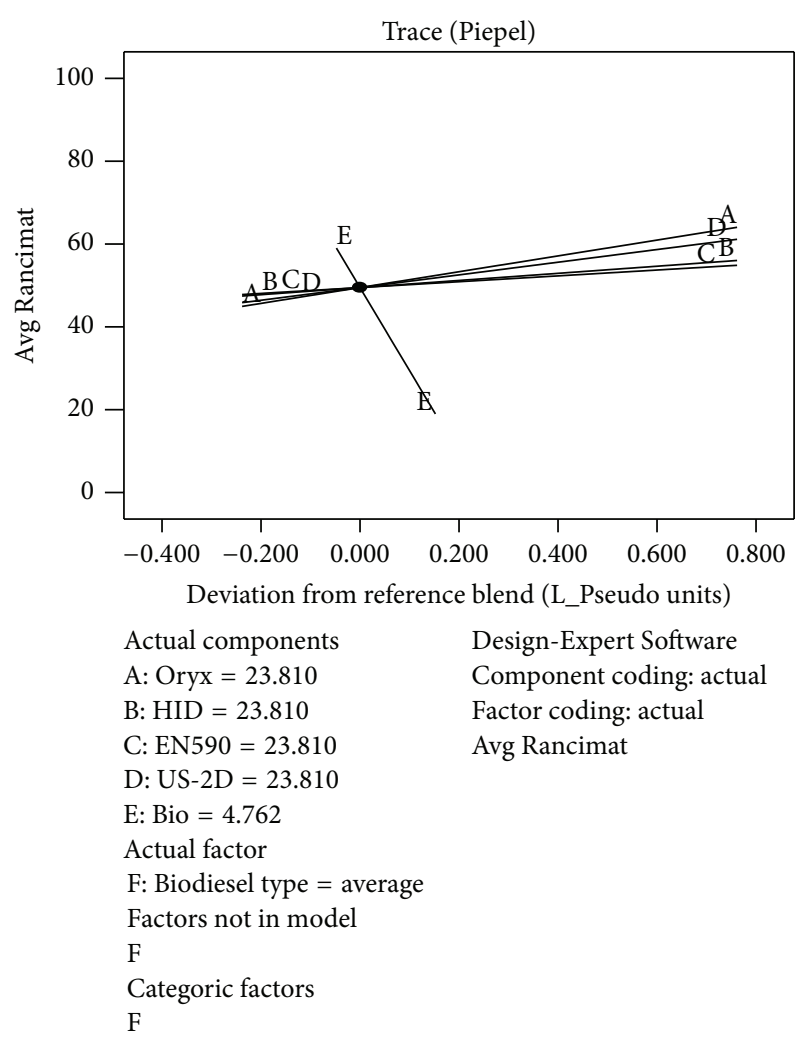

FIGURE 8: Rancimat results of the high stability FAME sample. (A = "summer type" GTL diesel, B = "winter type" GTL diesel, C = EN590 diesel, $\mathrm{D}=$ US 2-D content), $\mathrm{E}=$ FAME content.

these results are dependent on both the paraffinic base fuel and the FAME quality, and therefore a direct comparison with the results in this study is not possible.

FAME/GTL diesel blends were shown to be very stable, exceeding the stability of some FAME/petroleum-derived diesel blends.

\section{Conflict of Interests}

There is no conflict of interests related to the current paper.

\section{Acknowledgment}

The financial assistance of Sasol in sponsoring the current study is gratefully acknowledged.

\section{References}

[1] http://www.axens.net/document/11/gasoline-and-diesel...part1/english.html.

[2] J. B. Heywood, Internal Combustion Engine Fundamentals, McGraw-Hill, New York, NY, USA, 1988.

[3] http://www.bp.com/liveassets/bp_internet/australia/corporate australia/STAGING/local_assets/downloads_pdfs/f/LongTerm_Storage_ADF.pdf.

[4] G. Knothe, "Some aspects of biodiesel oxidative stability", Fuel Processing Technology, vol. 88, no. 7, pp. 669-677, 2007.
[5] T. Hartikka, U. Kiiski, M. Kuronen, and S. Mikkonen, "Diesel fuel oxidation stability: a comparative study," SAE Technical Paper 2013-01-2678, SAE International, 2013.

[6] A. J. Velaers and S. de Goede, "The properties and injector nozzle fouling performance of neat GTL and EN590 diesel blends in various diesel engines," SAE International Journal of Fuels and Lubricants, vol. 5, no. 3, pp. 1174-1186, 2012.

[7] S. De Goede, P. Roets, A. Velaers, J. Vermeulen, and C. Wilken, "The properties and injector nozzle fouling performance of GTL and EN590 diesel with RME and SME biodiesel," SAE Technical Papers, vol. 2, 2013.

[8] G. W. Mushrush, H. D. Willauer, J. W. Bauserman, and F. W. Williams, "Incompatibility of fischer-tropsch diesel with petroleum and soybean biodiesel blends," Industrial and Engineering Chemistry Research, vol. 48, no. 15, pp. 7364-7367, 2009.

[9] R. L. McCormick, M. Ratcliff, L. Moens, and R. Lawrence, "Several factors affecting the stability of biodiesel in standard accelerated tests," Fuel Processing Technology, vol. 88, no. 7, pp. 651-657, 2007.

[10] B. Terry, R. L. McCormick, and M. Natarajan, "Impact of biodiesel blends on fuel system component durability," SAE Technical Paper 2006-01-3279, 2006.

[11] R. R. Khoury, D. Ebrahimi, L. Hejazi, M. P. Bucknall, R. Pickford, and D. Brynn Hibbert, "Degradation of fatty acid methyl esters in biodiesels exposed to sunlight and seawater," Fuel, vol. 90, no. 8, pp. 2677-2683, 2011.

[12] J. D. Bacha and D. G. Lesnini, "Diesel fuel stability at $300^{\circ} \mathrm{F}$, in Proceedings of the 6th International Conference on Stability and Handling of Liquid Fuels, October 1997, http://www.fischertropsch.org.

[13] P. J. Berlowitz and R. J. Wittenbrink, "Improved stability Fischer Tropsch diesel fuel and a process for its production," International patent application WO 00/11116, March 2000.

[14] P. Schaberg, J. Botha, M. Schnell, H.-O. Hermann, N. Pelz, and R. Maly, "Emissions performance of GTL diesel fuel and blends with optimised engine calibrations," SAE Paper 2005-01-2187, 2005.

[15] P. Schaberg, D. D. Zarling, R. W. Waytulonis, and D. B. Kittelson, "Exhaust particle number and size distributions with conventional and Fischer Tropsch diesel fuels," SAE International Paper 2002-01-2727, 2002.

[16] T. L. Alleman, L. Eudy, M. Miyasato et al., "Fuel property, emission test, and operability results from a fleet of class 6 vehicles operating on gas-to-liquid fuel and catalyzed diesel particulate filters," SAE Paper 2004-01-2959, 2004.

[17] D. J. O'Rear, J. D. Bacha, and A. N. Tiedemann, "Thermally stable blends of Fischer Tropsch and LCO diesel fuel components," Energy and Fuels, vol. 18, no. 3, pp. 682-684, 2004.

[18] M. Kuronen, S. Mikkonen, P. Aakko, and T. Murtonen, "Hydrotreated vegetable oil as fuel for heavy duty diesel engines," SAE Technical Paper 2007-01-4031, 2007.

[19] J. Pullen and K. Saeed, "An overview of biodiesel oxidation stability," Renewable and Sustainable Energy Reviews, vol. 16, no. 8, pp. 5924-5950, 2012.

[20] J. Pullen and K. Saeed, "Experimental study of the factors affecting the oxidation stability of biodiesel FAME fuels," Fuel Processing Technology, vol. 125, pp. 223-235, 2014.

[21] H. D. Willauer, G. W. Mushrush, J. W. Bauserman, and F. W. Williams, "Synthetic fuels and biofuels: questionable replacements for petroleum," Naval Research Laboratory Report NRL/ MR/6180-08-9168, 2008, http://oai.dtic.mil/oai/oai?verb=getRecord\&metadataPrefix $=$ html\&identifier=ADA493237. 
[22] "EN 590 specification Automotive fuels-Diesel-Requirements and test methods".

[23] A. Blignaut, L. Collier, and M. Pretorius, "The impact of FischerTropsch diesel on the oxidation stability of biodiesel (FAME) blends," Journal of ASTM International, vol. 6, no. 8, Article ID JAI102579, 2009.

[24] R. A. Cherrillo, K. Dahlstrom, and E. C. Nelson, "Fuel compositions," US Patent 2011/0232169 A1, 2011.

[25] Stat-Ease, Design-Expert, Version 8.0.0, Stat-Ease, Minneapolis, Minn, USA, 2009.

[26] European Norm, "Fat and oil derivatives-Fatty Acid Methyl Esters (FAME) - determination of oxidation stability (accelerated oxidation test)," European Standard EN 14112, European Norm, 2003, http://www.bsigroup.com.

[27] European Standard, "Automotive fuels-fatty acid methyl ester (FAME) fuel and blends with diesel fuel-determination of oxidation stability by accelerated oxidation method," EN 15751:2014-06, 2014, http://www.bsigroup.com/.

[28] ASTM, "Standard test method for oxidation stability of middle distillate fuels-rapid small scale oxidation test (RSSOT)," ASTM Standard D7545, ASTM International, West Conshohocken, Pa, USA, 2009, http://www.astm.org.

[29] "ASTM D2274 Standard Test Method for Oxidation Stability of Distillate Fuel Oil (Accelerated Method)".

[30] Benchmarking of Biodiesel Fuel Standardization in East Asia Working Group, "Biodiesel fuel quality," in EAS-ERIA Biodiesel Fuel Trade Handbook, S. Goto, M. Oguma, and N. Chollacoop, Eds., pp. 27-62, ERIA, Jakarta, Indonesia, 2010.

[31] L. Botella, F. Bimbela, L. Martín, J. Arauzo, and J. L. Sánchez, "Oxidation stability of biodiesel fuels and blends using the Rancimat and PetroOXY methods. Effect of 4-allyl-2,6-dimethoxyphenol and catechol as biodiesel additives on oxidation stability," Frontiers in Chemistry, vol. 2, p. 43, 2014.

[32] S. V. Araújo, F. M. T. Luna, E. M. Rola Jr., D. C. S. Azevedo, and C. L. Cavalcante Jr., "A rapid method for evaluation of the oxidation stability of castor oil FAME: influence of antioxidant type and concentration," Fuel Processing Technology, vol. 90, no. 10, pp. 1272-1277, 2009.

[33] Y. L. MacHado, U. M. Teles, A. A. Dantas Neto, T. N. C. Dantas, and J. L. C. Fonseca, "Determination of antioxidant depletion kinetics using ASTMD 7545 as the accelerated oxidation method," Fuel, vol. 112, pp. 172-177, 2013. 


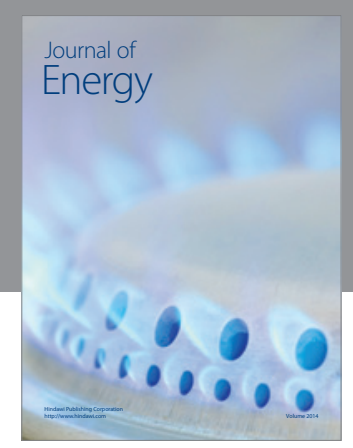

Journal of

Industrial Engineering
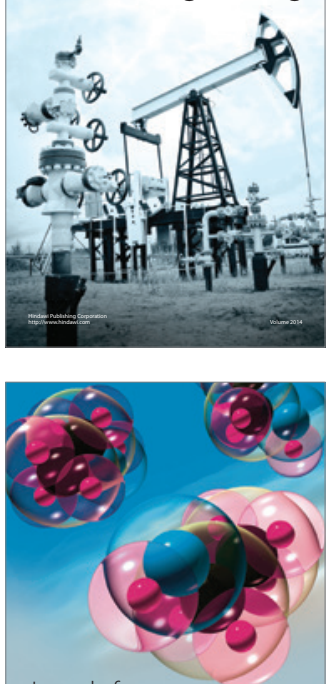

Fuels
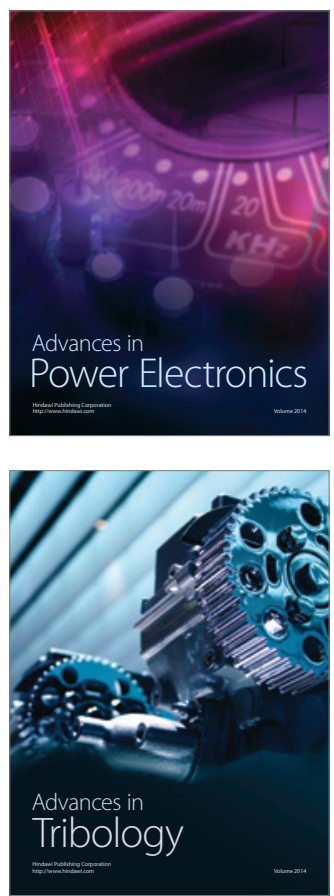

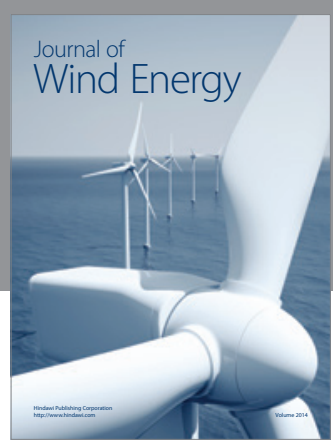

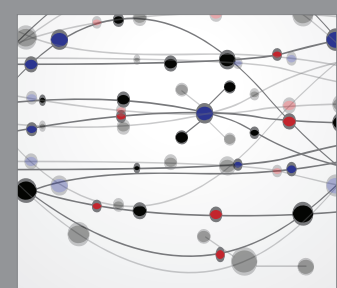

The Scientific World Journal

Submit your manuscripts at http://www.hindawi.com

Journal of

Structures
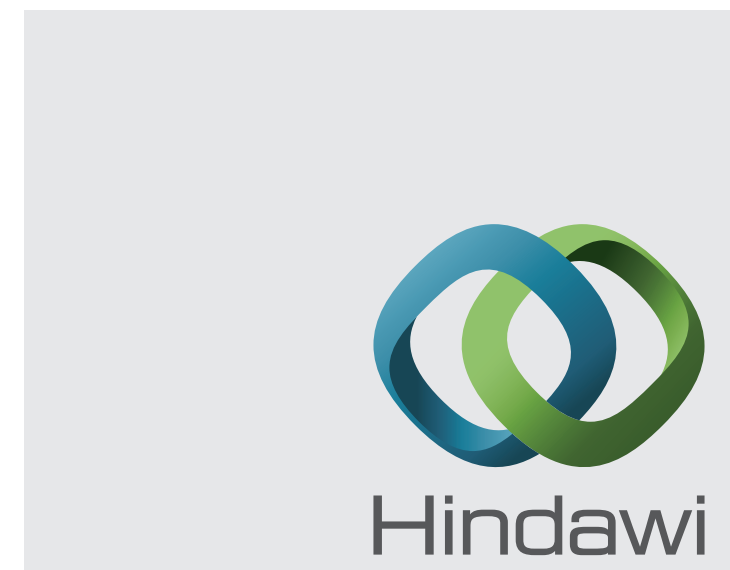

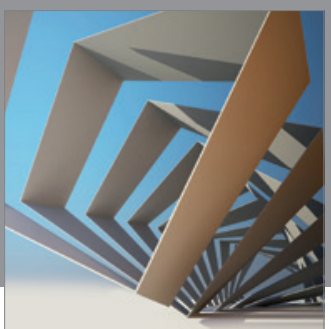

Rotating

Machinery
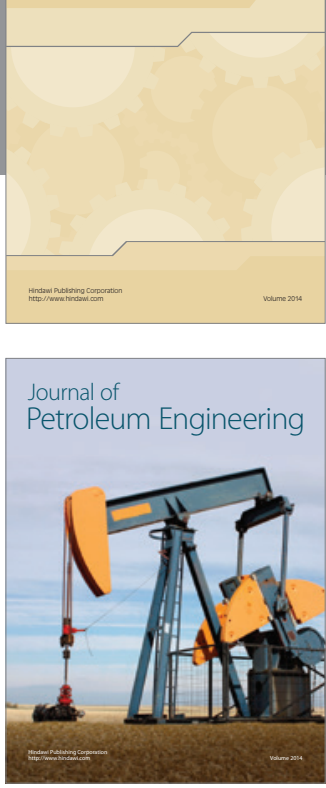

Journal of

Solar Energy
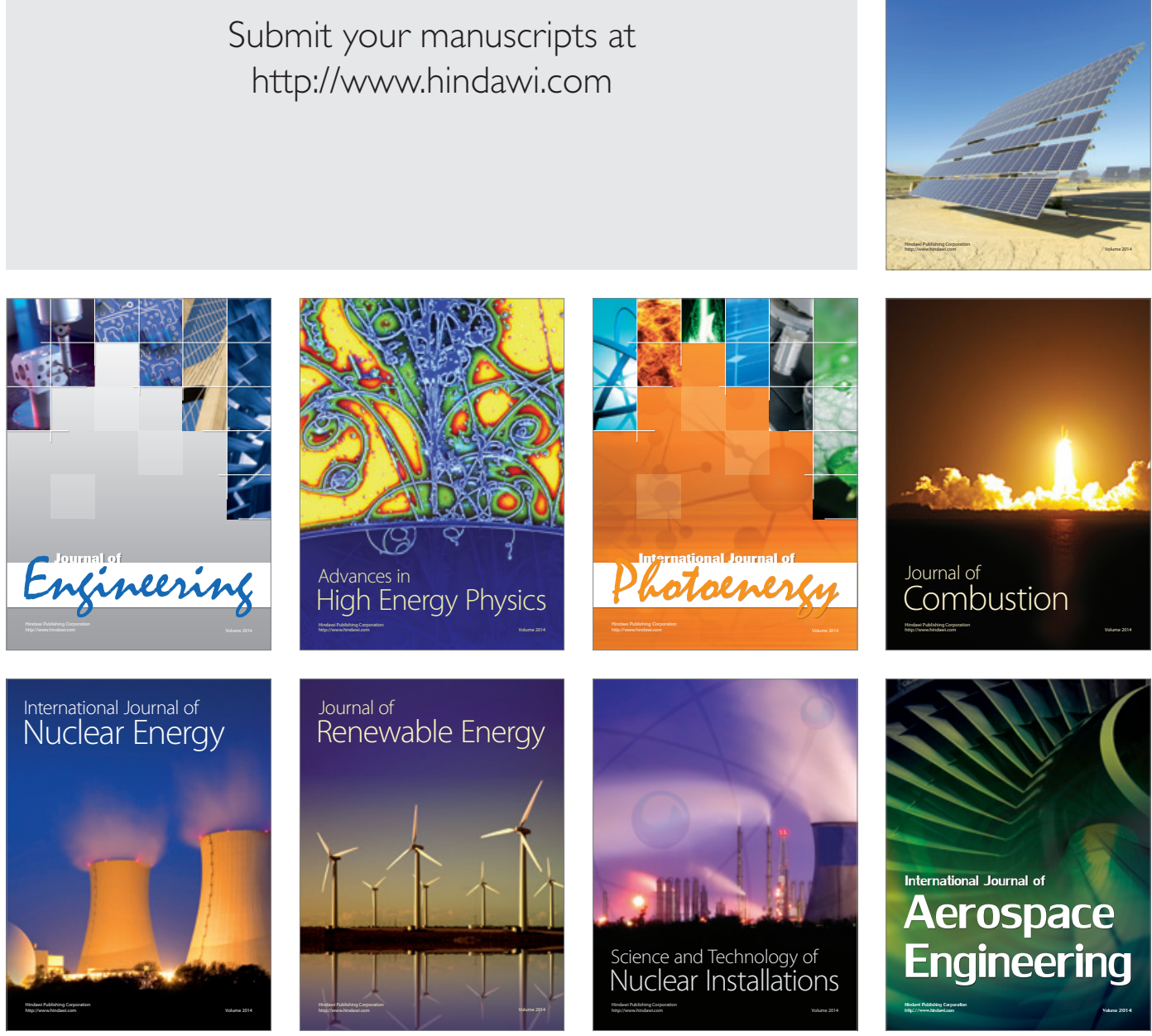